\title{
Iron economy in Chlamydomonas reinhardtii
}

\author{
Anne G. Glaesener ${ }^{1}$, Sabeeha S. Merchant ${ }^{1,2}$ and Crysten E. Blaby-Haas ${ }^{1 *}$ \\ ${ }^{1}$ Department of Chemistry and Biochemistry, University of California, Los Angeles, Los Angeles, CA, USA \\ 2 Institute of Genomics and Proteomics, David Geffen School of Medicine at the University of California, Los Angeles, CA, USA
}

\section{Edited by:}

Jean-Francois Briat, Centre National de la Recherche Scientifique, France

\section{Reviewed by:}

Francis-André Wollman, Centre

National de la Recherche

Scientifique/UPMC/IBPC, France

Francois-Yves Bouget, Centre

National de la Recherche

Scientifique, France

${ }^{*}$ Correspondence:

Crysten E. Blaby-Haas, Department

of Chemistry and Biochemistry,

University of California, Box 951569,

607 Charles E. Young Drive East,

Los Angeles, CA 90095-1569, USA

e-mail: cblaby@chem.ucla.edu
While research on iron nutrition in plants has largely focused on iron-uptake pathways, photosynthetic microbes such as the unicellular green alga Chlamydomonas reinhardtii provide excellent experimental systems for understanding iron metabolism at the subcellular level. Several paradigms in iron homeostasis have been established in this alga, including photosystem remodeling in the chloroplast and preferential retention of some pathways and key iron-dependent proteins in response to suboptimal iron supply. This review presents our current understanding of iron homeostasis in Chlamydomonas, with specific attention on characterized responses to changes in iron supply, like iron-deficiency. An overview of frequently used methods for the investigation of iron-responsive gene expression, physiology and metabolism is also provided, including preparation of media, the effect of cell size, cell density and strain choice on quantitative measurements and methods for the determination of metal content and assessing the effect of iron supply on photosynthetic performance.

Keywords: photosynthesis, transcriptome, ferredoxin, respiration, ferroxidases, photo-oxidative stress, acidocalcisome

\section{INTRODUCTION}

Although iron is relatively abundant in the earth's crust, inadequate access to this micronutrient often chronically limits photosynthesis in the ocean and on land. In oxygen-rich surface waters and neutral to alkaline soil, iron is present predominately in poorly soluble complexes, such as ferric oxides. The low bioavailability of iron complexes creates a major obstacle for photosynthetic organisms. Estimates indicate that iron limits phytoplankton growth in $40 \%$ of ocean waters (Moore et al., 2002) and that $30 \%$ of arable land is too alkaline for optimal iron uptake (Chen and Barak, 1982). This suggests that poor iron bioavailability causes consequential impacts on food chains, carbon sequestration and oxygen production.

Single-celled algae present a unique system for investigating how photosynthetic organisms respond to and cope with suboptimal iron nutrition. Specifically, in a laboratory setting, studying the subcellular response of plants to a deficient iron status can be complicated by the individual nutritional profile of each cell, tissue and organ type. Single-celled algae, on the other hand, such as the well-characterized green alga Chlamydomonas reinhardtii (referred herein as Chlamydomonas), are routinely grown in liquid cultures where the cell population and exposure to nutrients can be more homogenous. Chlamydomonas has been studied in the laboratory for well over 60 years as a convenient single-celled reference for understanding fundamental aspects of photosynthesis (Rochaix, 2002), including its specific relation to metal metabolism [reviewed in Merchant et al. (2006)]. The common laboratory strains are derived from a soil isolate, therefore, the natural environment of Chlamydomonas is close to that of land plants. Additionally, although the last common ancestor between Chlamydomonas and land plants such as Arabidopsis existed at least 700 million years ago (Becker, 2013), the photosynthetic apparatus are virtually identical. However, there are several metabolic differences; Chlamydomonas can oxidize acetate and exploits alternative bioenergetic routes such as hydrogen photoproduction and fermentation (Grossman et al., 2007).

This review focuses on our present understanding of iron nutrition in Chlamydomonas and on the preparation and use of iron-deficient and -limited media and common techniques to study physiology, gene expression and metabolism in Chlamydomonas. An effort is also made to point out caveats associated with these types of studies for all investigators to consider.

\section{IRON NUTRITION IN CHLAMYDOMONAS}

Like land plants, algae have two especially iron-rich organelles, the chloroplast and the mitochondrion. Both organelles house numerous iron-dependent proteins whose functions are essential in the electron transfer pathways of the bioenergetic membranes in those compartments. In addition, iron is a component of many proteins involved in other essential processes such as reactive oxygen detoxification, fatty acid metabolism, and amino acid biosynthesis. Assuming a 1:1 stoichiometry of the electron transfer complexes [dimers for photosystem II (PSII) and the cytochrome $b_{6} f$ complex and a monomer for photosystem I (PSI)], linear electron flow from PSII to ferredoxin is estimated to require 30 iron ions (if plastocyanin is present, and 31 iron atoms if cytochrome $c_{6}$ is present) (Blaby-Haas and Merchant, 2013). Again assuming 1:1 stoichiometry (monomers for complexes I, II, and IV, and a dimer for complex III), mitochondrial electron transport requires 50 iron atoms, over half contained within complex I (Xu et al., 2013). Although electron transfer in respiration appears to require more iron than does photosynthesis, the chloroplast is the dominant sink for iron in the oxygen-evolving plant cell, where this cofactor is 
concentrated in the abundant iron-dependent proteins of the thylakoid membrane.

The contribution of iron-dependent proteins in other cellular compartments to the cellular iron quota may be relatively small, but they are also essential for fitness or survival. These enzymes participate in DNA synthesis and repair [ribonucleotide reductase (cytosol) and DNA glycosylases (nucleus)], metabolite synthesis [cytochrome P450s (endoplasmic reticulum), aldehyde oxidase (cytosol), xanthine dehydrogenase (cytosol)], molybdopterin synthesis [Cnx2 (cytosol)], fatty acid metabolism [fatty acid desaturases (endoplasmic reticulum)] and reactive oxygen species detoxification [peroxidases (multiple compartments including peroxisome, Golgi, and cytosol)], just to name a few. Therefore, a delicate balance exists to ensure an appropriate amount of iron or iron-bound cofactor such as heme is present throughout the cell for the maturation of each iron-dependent protein.

As a facultative photoheterotroph, Chlamydomonas can generate ATP from either photosynthesis or respiration depending on the presence of light and carbon source. This characteristic provides a unique and powerful experimental system to explore the effect of iron status on bioenergetic metabolism and vice versa. In particular, during the two major trophic states, photoautotrophic and photoheterotrophic, Chlamydomonas cells respond to iron status with acutely different physiologies (Figure 1). During the photoheterotrophic state, the cells are provided with light, $\mathrm{CO}_{2}$, and acetate. When iron becomes a limiting resource, competition for iron acquisition between the chloroplast and the mitochondria ensues. In response, the cell maintains respiration while decreasing the photosynthetic contribution to the bioenergetics of the cell, a phenomenon that may rely on preferential allocation of iron to the mitochondrion or recycling of iron from the chloroplast to the mitochondrion. In contrast, in the absence of acetate, photosynthetic activity is maintained, as seen by a less pronounced decrease in chlorophyll (Chl) content and maintenance of the maximum quantum efficiency of PSII (expressed by $\left.F_{v} / F_{m}\right)$ (Figures 1A,B) (Terauchi et al., 2010; Urzica et al., 2012).

To understand these phenomena and discover the underlying mechanisms, the study of iron homeostasis in Chlamydomonas is routinely performed in the context of four graded iron nutrition stages: excess, replete, deficient and limited. These states were delineated by the evaluation of phenotype and iron-responsive gene expression in response to controlled medium iron content (described in more detail in the following sections and summarized in Table 1).

Specifically, components of the iron-uptake pathway are routinely used as sentinel genes for iron status. In contrast to land plants, the main iron uptake pathway in Chlamydomonas (based on transcript and protein abundance) is the fungal-like ferroxidase-dependent ferric transporter complex consisting of FOX1 (the ferroxidase) and FTR1 (the permease) (Figure 2). The copper-containing enzyme FOX1 catalyzes the oxidation of $\mathrm{Fe}(\mathrm{II})$ to $\mathrm{Fe}(\mathrm{III})$, similar to the yeast and human enzymes, Fet3p and ceruloplasmin, respectively (Herbik et al., 2002; La Fontaine et al., 2002). FOX1 is presumed to form a complex with the permease FTR1, which transports the ferric iron provided by FOX1 into the cytosol (Terzulli and Kosman, 2010). FOX1 expression responds
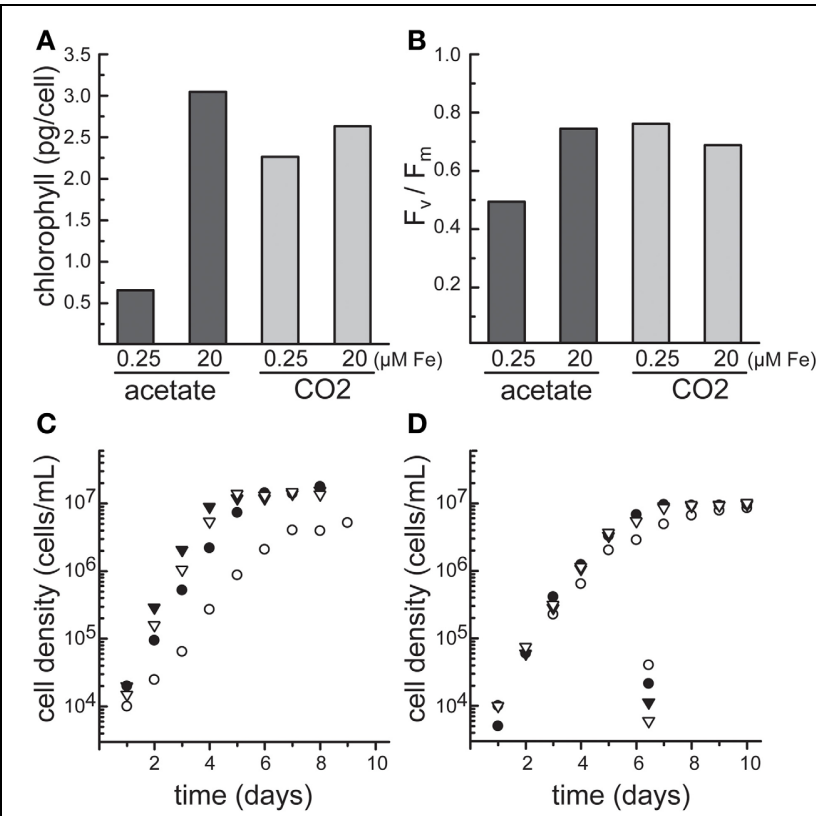

D

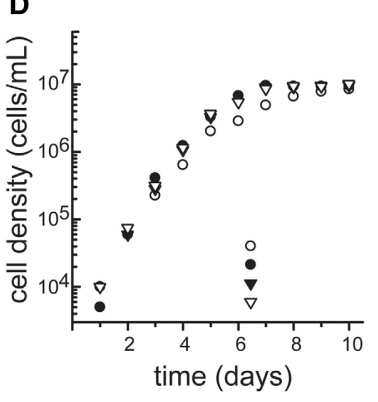

FIGURE 1 | The growth of Chlamydomonas CC-4532 in response to iron supplementation depends on the carbon source. Cells were cultured in TAP for photoheterotrophic growth (acetate) or TP for photoautotrophic growth $\left(\mathrm{CO}_{2}\right)$ using the revised trace metal supplement (Kropat et al., 2011) at $24^{\circ} \mathrm{C}$ and shaken at $180 \mathrm{rpm}$ under continuous illumination of $70-80 \mu \mathrm{mol} / \mathrm{m}^{2} \mathrm{~s}$, and bubbled with sterile air. (A) Determination of chlorophyll content and (B) maximum quantum efficiency of photosystem II $\left(F_{v} / F_{m}\right)$. Aliquots of cells grown photoheterotrophic (dark gray) and photoautotrophic (light gray) were removed from the culture during the logarithmic growth phase $\left(\sim 4 \times 10^{6}\right.$ cells $\left./ \mathrm{ml}\right)$. (C)

Photoheterotrophically and (D) photoautotrophically grown cells at $0.25 \mu \mathrm{M}$ (open circles), $1 \mu \mathrm{M}$ (filled circles), $20 \mu \mathrm{M}$ (filled inverted triangles) and $200 \mu \mathrm{M}$ Fe (filled inverted triangles) were counted with a hemocytomer for estimation of growth rates.

quickly to changes in iron nutrition ahead of any observable effects on physiology and thus provides a convenient and robust marker for iron status (Figure 3).

It should be noted that the following iron nutrition stages are described for cells grown photoheterotrophically (light and acetate). The same stages can be described for phototrophic cells (light and $\mathrm{CO}_{2}$ ), but the iron concentration thresholds are distinct, as is the cellular response to those concentrations. These stages are also likely distinct for cells grown purely heterotrophically (dark and acetate), but this phenomenon has not yet been systematically studied.

\section{STAGE 1: IRON EXCESS}

In the iron excess stage ( $200 \mu \mathrm{M}$ medium iron content), the cells will over-accumulate iron, as compared to the iron-replete stage (Long and Merchant, 2008; Terauchi et al., 2010). This observation is in contrast to the copper-excess situation where the cells only take up as much copper as needed despite over 500-fold excess in the medium (Page et al., 2009). Although the culture does not display any visible phenotype associated with iron excess, the cells are unable to grow at high photon flux density $\left(500 \mu \mathrm{mol} / \mathrm{m}^{2} \mathrm{~s}\right.$ at the surface of a petri dish) (Long and 
Table 1 | Summary of the iron nutrition stages in Chlamydomonas distinguished by phenotype and sentinel gene expression.

\begin{tabular}{|c|c|c|c|c|c|c|c|}
\hline & \multicolumn{4}{|c|}{ Photoheterotrophic } & \multicolumn{3}{|c|}{ Photoautotrophic } \\
\hline Fe in the media $(\mu \mathrm{M})$ & 200 & 20 & $1-3$ & $0-0.5$ & 20 & $1-3$ & $0-0.5$ \\
\hline Growth & $\begin{array}{l}\text { Impaired only under } \\
\text { light stress }\end{array}$ & & & Impaired & & & $\begin{array}{l}\text { Slightly } \\
\text { impaireo }\end{array}$ \\
\hline Fe atoms/cell $\left(\times 10^{7}\right)$ & $50-100$ & $8-20$ & $2-12$ & $1-4$ & 14 & $6-9$ & 3 \\
\hline
\end{tabular}

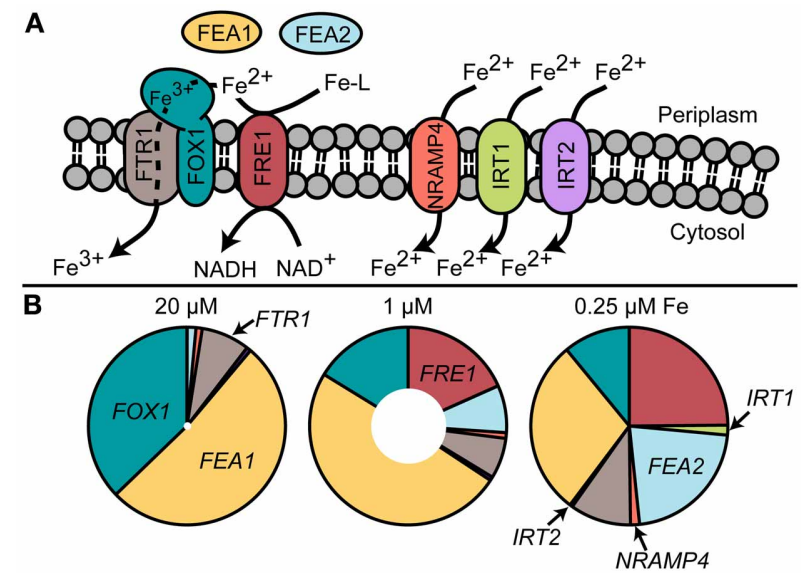

FIGURE 2 | (A) Known and putative iron uptake pathways in Chlamydomonas and (B) transcript abundance of uptake components estimated by RNA-Seq (Urzica et al., 2012). The inner white circles represent total transcript abundance relative to $0.25 \mu \mathrm{M}$ iron.

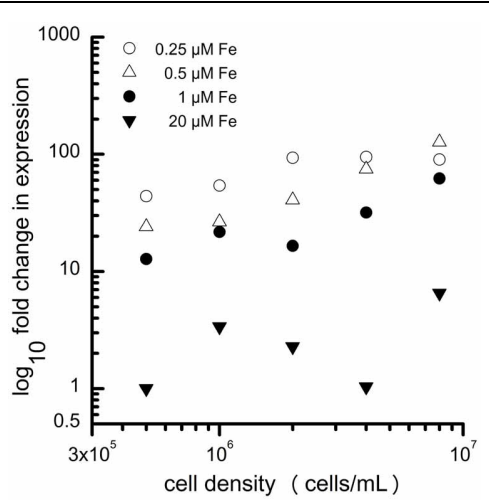

FIGURE 3 | Expression of FOX1 depends both on extracellular iron content $(0.25 \mu \mathrm{M}$, open circles; $0.5 \mu \mathrm{M}$, filled triangles; $1 \mu \mathrm{M}$, filled circles; $20 \mu \mathrm{M}$, filled inverted triangles) and the number of cells per $\mathbf{m L}$. The increased expression of FOX1during growth of the batch culture likely reflects the reduced Fe availability on a per cell basis. Adapted from Urzica et al. (2012).

Merchant, 2008). This result suggests that the higher iron content of the cells, which is 2- to 5-fold higher than in replete cells, exacerbates damage caused by photo-oxidative stress and that there may be a pool of reactive iron in the chloroplast. In contrast to mammals and higher plants, iron excess does not affect the abundance of ferritin in Chlamydomonas, leading to the conclusion that ferritin is not the major iron storage molecule in the cell (Busch et al., 2008; Long et al., 2008). For Chlamydomonas, there are no known mechanisms for iron export, presumably because this high iron concentration is not typically experienced in nature and there is no need to establish pathways to deal with the excess.

Based on Mössbauer spectroscopy of iron-replete cells, Semin et al. found that Chlamydomonas cells contain an unusally high amount of ferrous iron. The authors have postulated that instead of typical iron storage proteins such as ferritin or siderophores, which would bind ferric iron, iron is stored in vacuoles as in yeast (Semin et al., 2003). This compartment may in fact be the acidocalcisome, which is an acidic, calcium- and polyphosphate-rich, membrane-bound, lysosome-related organelle (Ruiz et al., 2001; Docampo et al., 2005). Indeed, in the green alga Dunaliella salina and the red alga Cyanidium caldarium, intracellular iron is found in acidic vacuoles (Paz et al., 2007; Nagasaka and Yoshimura, 2008).

\section{STAGE 2: IRON REPLETE}

The standard growth medium for Chlamydomonas contains 18$20 \mu \mathrm{M}$ iron (depending on the trace supplement) (Hutner et al., 1950; Kropat et al., 2011). In both trace mixes, iron is supplied as an EDTA chelate, which is used to maintain iron in solution, thereby facilitating uptake. However, it should be mentioned that for the Hutner's trace mix, $18 \mu \mathrm{M}$ iron is the concentration of iron added to the mix, but because of ferric iron precipitation during preparation, there is batch-to-batch variation, and the concentration of soluble iron may be closer to $10 \mu \mathrm{M}$ (Kropat et al., 2011). Recently, a revised trace metal supplement for Chlamydomonas was formulated (Kropat et al., 2011). Using the cellular content of metals during growth in the replete condition, the trace metal composition was adjusted to supply a 3 -fold excess of each nutrient. Some components not utilized by Chlamydomonas found in the Hunter's trace mix were removed, such as cobalt and boron, and the concentrations of other metals, such as zinc and manganese were reduced. Several benefits are apparent with use of the new formulation. The cells have an increased growth rate, and the supplement is more stable and less time consuming to prepare. Instead of combining the mineral nutrients into a single stock, each component is stored separately and added freshly while preparing media. In terms of iron nutrition, the greatest benefit of the revised mix is the absence of iron precipitation (over a 5 years period). 
As the culture reaches stationary growth, the cells in replete medium have consumed (depending on the strain) $10-30 \%$ of the medium iron content (Kropat et al., 2011; Page et al., 2012). This "luxury" consumption is characterized by basal low level expression of the genes encoding the high-affinity FOX1/FTR1 ferric iron transporter and negligible expression of the putative secondary iron transporters NRAMP4, IRT1, and IRT2 (Urzica et al., 2012). In the replete stage, Chl concentration has been measured at roughly $2.5 \mathrm{pg} / \mathrm{cell} \mathrm{Chl}$ (Moseley et al., 2002; Page et al., 2012; Urzica et al., 2012). However, the ratio of Chl per cell or Chl per protein is affected by the incident illumination and the strain genotype.

\section{STAGE 3: IRON DEFICIENT}

As the iron content of the medium is reduced to around $1-3 \mu \mathrm{M}$, the cells begin to experience iron deficiency. The expression of iron uptake pathways is dramatically induced. Increased abundance of FOX1 at either mRNA or protein levels is commonly used as a sentinel marker for iron-deficiency. Well characterized primers for qPCR and antibodies for immunoblot analysis are available (Herbik et al., 2002; La Fontaine et al., 2002; Allen et al., 2007a). At this concentration of iron supply, the cells are usually not chlorotic and photosynthetic complex abundance is generally not affected (Moseley et al., 2002). Of course, depending on genotype, in some strains the lower end of this concentration range may result already in symptoms of limitation (see below), such as marginal chlorosis and a very mild impact on abundance of photosynthetic complexes. In general, this stage is differentiated from the iron-limited state by the lack of a growth phenotype.

Despite the absence of chlorosis in the iron-deficient state, spectroscopic measurements revealed some changes within the chloroplast. Specifically, fluorescence rise and decay kinetics (Kautsky curves) indicate that re-oxidation of the plastoquinone (PQ) pool is slower in the iron-deficiency situation (Moseley et al., 2002). This has been attributed to some loss of function of iron-containing electron transfer complexes downstream of the PQ pool, such as the cytochrome $b_{6} f$ complex, PSI or ferredoxin. The relatively exposed [4Fe-4S] clusters of PSI are prime candidates.

Structural changes in the PSI-LHCI complex accompany iron deficiency, presumably to compensate for reduced PSI function. These modifications to the complex result in reduced energy transfer from the accessory antenna to the reaction center (Moseley et al., 2002). This results both from dissociation of PsaK, a connector between PSI and LHCI, from PSI and proteolysis of individual Lhca subunits in LHCI (Ben-Shem et al., 2003; Naumann et al., 2005). The signal transduction pathway leading to the structural modification of PSI-LHCI is not known, nor is the mechanism of PsaK and Lhca degradation. Mixing experiments indicate that degradation does result from induced proteolysis (Moseley et al., 2002). One idea that has been put forward regarding sensing of iron status by PSI is that it may occur by occupancy of the Chl binding sites in PsaK. If these sites are low affinity, they may be sensitive indicators of flux through the Chl biosynthetic pathway, which is dependent on iron at the rate-limiting step catalyzed by aerobic cyclase (Tottey et al., 2003).
Based on genome-wide expression profiling using RNA-Seq methodology, 78 genes displayed at least a 2-fold difference in transcript abundance between this stage $(1 \mu \mathrm{M} \mathrm{Fe})$ and the replete stage (Urzica et al., 2012). Since many organisms occupy a niche that allows them to survive in just barely sufficient iron, the transcriptome of this state is clearly relevant to the impact of marginal iron nutrition on crop yields and primary productivity. The two largest functional groups (for this particular dataset) represented in the iron-deficient stage encode proteins with known or predicted function in metal transport (17\%) and the redox/stress response (25\%). This includes the upregulation of genes involved in iron transport, like the ferric reductase FRE1, the high-affinity iron-uptake system (comprising FOX1 and FTR1), the transcripts for the algal-specific proteins FEA1 and FEA2, and the putative secondary iron transporters NRAMP4 and IRT2. The expression of a Mn-dependent superoxide dismutase is also highly induced. The transcripts of only four genes were significantly reduced in abundance during this condition. One of these is FDX5, an anaerobically-induced chloroplast-targeted ferredoxin which contains a [2Fe-2S] cluster (Jacobs et al., 2009). The reduction of FDX5 transcript abundance may serve to spare iron.

The large proportion of redox/stress-related transcripts at this stage of iron nutrition, which is visually asymptomatic, may reflect an anticipatory response to incipient stress associated with changes in light harvesting and reduced rate of electron transfer downstream of the PQ pool. Additionally, these transcripts may be related to compromised PSI, which can produce superoxide by the photoreduction of oxygen. Solvent-exposed iron-sulfur clusters are particularly sensitive to superoxide and are consequently destroyed releasing ferric iron. If not immediately chelated, the free iron can react with hydrogen peroxide creating the hydroxyl radical, a highly cytotoxic molecule, which cannot be detoxified enzymatically. Indeed, expression of the two ferritin genes in Chlamydomonas is induced during iron deficiency. The ferritins localize to the chloroplast, but only ferritin 1 appears to increase in abundance in response to iron-deficiency (Busch et al., 2008; Long et al., 2008). Although ferritins are typically regarded as iron storage complexes, neither of the two Chlamydomonas complexes appears to contain significant amounts of iron when cells were grown in iron-deficient medium, leading to the conclusion that ferritin buffers instead of stores iron liberated within the chloroplast. As a unicellular organism, iron homeostasis is focused on distribution at a sub-cellular level, including partitioning to the mitochondria vs. the chloroplast, and this may account for the unique response of ferritin within the chloroplast.

\section{STAGE 4: IRON LIMITATION}

As the iron content of the medium is reduced below about $0.5 \mu \mathrm{M}$, cells enter the iron-limited stage, where cell growth is inhibited due to limiting nutritional supply of iron. Although the iron transport pathways are still highly expressed, and at a higher level than in the deficiency state (Figure 3), the cells are markedly chlorotic, corresponding to a decrease in Chl of about 2- to 4-fold, and the growth rate is reduced (Figure 1). Concurrently, multiple iron-containing proteins in the chloroplast are reduced in abundance. These include PSI (12 iron atoms), the cytochrome 
$b_{6} f$ complex (12 iron atoms) and ferredoxin ( 2 iron atoms), and as a result, iron-limited cells exhibit a severe block in photosynthesis (Moseley et al., 2002; Page et al., 2012; Urzica et al., 2012). The noticeable loss of iron-bound photosynthetic complexes is generally only seen for cells grown in media containing acetate as carbon source, whereas photoautotrophically grown cultures maintain photosynthetic performance and retain these complexes for an extended period of time during iron-limitation. During photoheterotrophic iron-limited growth, subunits of respiratory complexes localized in the mitochondria change in abundance, as shown by immunoblot analysis and comparative quantitative proteomics (Naumann et al., 2007; Terauchi et al., 2010). The abundance of complex I subunits is decreased, whereas subunits of complexes III and IV increase. In the absence of acetate, abundances of respiratory complexes remain unchanged during iron-limitation.

Urzica et al. found a large number of genes with increased transcript abundance (at least 2-fold difference; 2050 genes) during this stage $(0.25 \mu \mathrm{M})$ relative to iron replete, underscoring the stress induced by iron limitation (Urzica et al., 2012). As seen in the iron-deficient dataset, the most dramatically increased transcripts are those involved in iron transport and those encoding Mn-dependent superoxide dismutase (Urzica et al., 2012). The large number of differentially abundant transcripts during this condition also highlights the value of studying the transcriptome of the iron-deficient state, where only 78 RNAs are significantly changed in abundance. It is more likely that these 78 RNAs include the direct targets of iron nutrition acclimation rather than secondary stress responses. Indeed, several transcriptome studies of iron-starved land plants have had to contend with large sets of transcripts with changed abundance (Thimm et al., 2001; Zheng et al., 2009). The mechanical stress of transferring plants from iron-sufficient to -deprived medium (Buckhout et al., 2009) and the cumulative response from different cell types and tissue often obscures the primary iron responses.

\section{COMMON METHODS FOR STUDYING IRON NUTRITION IN CHLAMYDOMONAS}

Three basic techniques are generally used to generate poor iron nutrition in the laboratory. The first is to limit the available iron in the medium by chelators. For work with yeasts like $S$. cerevisiae and Schizosaccharomyces pombe, iron-chelators such as $2,2^{\prime}$-dipyridyl and bathophenanthroline disulfonic acid, are often used to generate a state of poor iron nutrition in vivo (Eide et al., 1996; Pelletier et al., 2005; Mercier et al., 2006; Jo et al., 2009). Some studies with plants like Arabidopsis thaliana have combined the use of chelators like ferrozine with the strategy of creating iron deficiency by omitting iron from the media (Vert et al., 2002; Lanquar et al., 2005; Yang et al., 2010). For Chlamydomonas, some studies have used the chelators ferrozine and ethylenediamine-N,N'-bis(2-hydroxyphenyl)acetic acid (EDDHA) (Xue et al., 1998; Weger, 1999; Weger and Espie, 2000; Rubinelli et al., 2002). However, when using chelators or evaluating studies that solely used chelators to achieve iron depletion, several caveats should be kept in mind. As with all metal chelators, these molecules are not specific to iron and will bind other metal ions (Kroll et al., 1957; Stookey, 1970), possibly leading to observations not specifically caused by iron depletion. In addition, the cells may be able to compete with the chelator leading to slower iron uptake, which may affect how the cells respond as compared to an actual omission of iron from the media. In some ways, however, the use of chelators could be a more appropriate approach to the study of iron homeostasis, because in most environments poor iron nutrition is due to competition between iron uptake pathways and natural ligands in contrast to the absence of iron.

The second technique is to limit intracellular iron by using an iron-transport mutant. This approach has not been routinely employed for work with Chlamydomonas but is commonly used in other organisms such as yeast and land plants. In A. thaliana, a mutant of the iron transporter IRT1 was used to elucidate the role of iron-nutrition on lateral root development (Giehl et al., 2012), gene expression (Wang et al., 2007), and circadian rhythm (Hong et al., 2013; Salomé et al., 2013). In the yeast S. cerevisiae, the fet 3 fet 4 double mutant, lacking both the high and low affinity iron transport pathway, is very sensitive to poor iron nutrition (Dix et al., 1994). This mutant has been used to study siderophore uptake (Lesuisse et al., 1998) and to investigate the relationship between iron homeostasis and an anti-malaria drug (Emerson et al., 2002). Although the use of iron transport mutants is a convenient method to achieve cellular iron depletion, iron will likely enter the cell via other routes and uptake of other metal ions can be affected in the mutant.

The third and preferable approach is to control the amount of iron added to the medium, described in more detail in section Preparing Media. Of course, in each of these cases, one has to worry about whether deficiency in one metal affects the intracellular concentration of other metal ions. For instance, nonselective transporters may be induced, which will inadvertently bring in multiple metal ions. The cell may purposefully change the concentration of other metals as seen for iron and manganese and for zinc and copper levels in Chlamydomonas (Allen et al., 2007b; Malasarn et al., 2013). Therefore, it is imperative to measure all intracellular metal concentrations during iron nutrition experiments (see section Metal Measurement).

\section{PREPARING MEDIA}

Chlamydomonas is routinely cultured in a simple, defined medium where the concentration of metal ions can be selectively controlled. Popular media include Sueoka's high salt medium (HS or HSM) and Tris-phosphate medium (TP), both of which can be supplemented with the carbon source acetate (HSMA and TAP, respectively). The largest difference between the two media is the presence of Tris(hydroxymethyl)aminomethane (Tris) in TP and a roughly 14-fold higher concentration of potassium and phosphate in HSM. TAP/TP has a higher capacity to buffer $\mathrm{pH}$ changes in the culture compared to HSMA/HSM, which should be considered when choosing a medium, since the $\mathrm{pH}$ of the medium affects the availability of iron. Both types of media are routinely used for iron nutrition studies in Chlamydomonas. Indeed, TAP and HSM are generally used to compare photoheterotrophic and photoautotrophic growth. However, because the compositions of the two media are different, using TAP and TP or HSMA and HSM is preferred. 
Because of high metabolic demand for iron, iron depletion in laboratory media is relatively easy to accomplish in Chlamydomonas. However, several precautions should be followed to ensure that the amount of iron in the medium is tightly controlled and the experiments are therefore reproducible, i.e., the only iron present is that which is consciously added. Most recent iron metabolism studies of Chlamydomonas employ the media preparation methods detailed in (Quinn and Merchant, 1998) for achieving copper deficiency. In summary, the use of clean glassware and plasticware is of paramount importance. All culture flasks and reusable plasticware are rinsed at least twice with $6 \mathrm{~N} \mathrm{HCl}$ to displace metal ions and rinsed six times with MilliQ-purified water to remove the $\mathrm{HCl}$. High-purity chemicals are used to make iron-free stock solutions, which are stored in metal-free plasticware. Certificates of analysis specifying the trace metal composition are generally available before purchase of the stock chemicals and can be used to estimate the amount of contaminating metals in the prepared medium. These chemicals should be kept separate from other laboratory chemicals to avoid accidental metal contamination. The preparation of solid iron-deficient media requires washing of the agar with EDTA to remove contaminating metal ions (Figure 4). At all times, effort should be made to avoid contamination with metals (wear gloves, no metal spatulas and protection from dust). Ideally, irondeficient media prepared in glass flasks should be used immediately. It is recommended that the media not be stored for more than a couple of days. Even though the flasks are acid washed, there will be residual metal ions remaining in the glass, which will leach into the medium over time (Cox, 1994).

\section{The use of $\mathrm{pH}$}

Alkaline $\mathrm{pH}$ is commonly employed in iron nutrition experiments with soil-grown plants that rely on acidification and reduction to

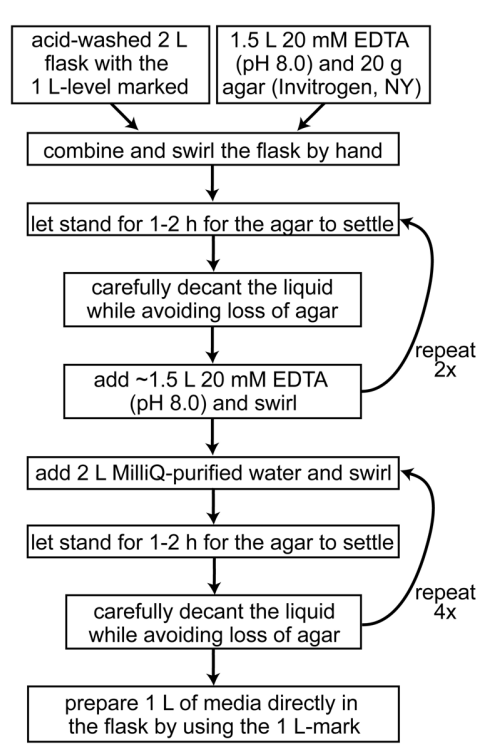

FIGURE 4 | Workflow for the preparation of iron-depleted solid growth media for Chlamydomonas. solubilize iron (i.e., Strategy I plants). This strategy has not been generally applied to Chlamydomonas, because of the ease with which the iron concentration in the medium can be controlled.

\section{STRAINS}

The genotype of each "wild-type" Chlamydomonas strain can have a noticeable effect on a strain's tolerance to poor iron nutrition. Most of the commonly used laboratory strains appear to be descendants of a cross between two divergent spores from the original isolate, and the resulting progeny may have one or the other of two distinct haplotypes at any given locus (Gallaher et al., manuscript in preparation). In practice, this means that even closely related strains, such as CC-4402 and CC-4532, can have thousands of SNPs relative to each other, and will exhibit observable phenotypic differences (Figure 5).

The largest difference between strains in terms of iron nutrition is the presence or absence of a cell wall. Some researchers have chosen to employ a cell wall-less strain in their studies to avoid overestimation of iron uptake rates caused by iron bound to the cell wall (Lynnes et al., 1998). However, it was later found that two key components of the iron assimilation pathway are soluble proteins secreted to the periplasmic space between the plasma membrane and cell wall. Expression of the genes encoding these algal-specific proteins, FEA1 and FEA2, is significantly induced during iron deficiency, and in a cell wall-less strain, these proteins are lost to the medium (Allen et al., 2007a). Although we do not know the function of these periplasmic proteins, it is hypothesized that they may bind iron and may serve to concentrate iron (whether $\mathrm{Fe}$ (II) or $\mathrm{Fe}$ (III) is not known) in proximity to the plasma membrane assimilatory transporters. A significant consequence of the loss of the FEA proteins into the medium is increased sensitivity of these strains to iron depletion (strain CC-425 in Figure 5).

\section{CELL SIZE}

Metal and Chl content are commonly reported on a per cell basis for Chlamydomonas. This convention can complicate comparisons of iron homeostasis studies employing different Chlamydomonas strains or cells grown under different growth regimes as cell size can vary between laboratory strains and growth conditions. Cell size was reported to be affected by trophic status (Terauchi et al., 2010), nutrient stress (Zhang et al., 2002; Kropat et al., 2011), $\mathrm{CO}_{2}$ concentration (Vance and Spalding,

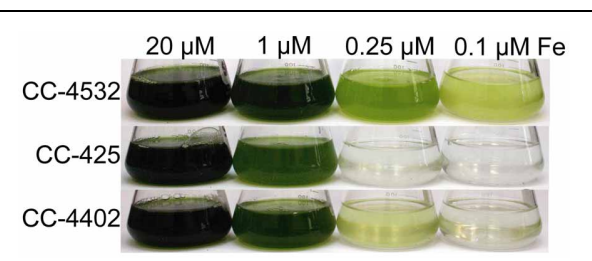

FIGURE 5 | Growth of different Chlamydomonas strains in response to iron supply. CC-4532 and CC-4402 are cell wall-containing strains, whereas CC-425 represents a cell wall-less strain. Cultures were inoculated at $1 \times 10^{4}$ cells $/ \mathrm{mL}$ and grown for 10 days in TAP (Tris-acetate-phosphate) supplemented with iron to the indicated concentrations at $24^{\circ} \mathrm{C}$ and shaken at $180 \mathrm{rpm}$ under constant illumination of $60-80 \mu \mathrm{mol} / \mathrm{m}^{2} \mathrm{~s}$. 
2005), HSM compared to TAP media (Fischer et al., 2006), light quality (Murakami et al., 1997), light intensity (Matsumura et al., 2003) as well as during the cell cycle (Umen, 2005). Additionally, cell size can vary between mutant and parent. For instance, a ferritin knockdown mutant was found to be almost 2-fold bigger in size than the wild-type strain (Busch et al., 2008).

\section{CELL DENSITY}

In general, it is advisable to control for cell density rigorously during sampling of cells for molecular analyses so that external iron concentration can be used as a proxy for intracellular iron content. A typical laboratory culture of Chlamydomonas will consume iron equivalent to about $3 \mu \mathrm{M}$ as it goes from inoculation to stationary phase (Page et al., 2012). Therefore, in medium containing iron in this concentration range (or lower), expression of the nutritional iron regulon is dependent on the cell density (Figure 3). As the cells in culture divide, the ratio of medium iron per cell decreases, and expression of genes involved in iron assimilation steadily increases (Urzica et al., 2012). This relationship is not evident in medium containing excess iron (see $20 \mu \mathrm{M}$ samples in Figure 3) where the FOX1 marker gene is expressed at a very low basal level. Interestingly, in fully replete media, during logarithmic phase, the demand for intracellular iron exceeds the capacity of the iron uptake and metabolism pathway, resulting in transient iron deficiency (Page et al., 2012).

\section{METAL MEASUREMENT}

Element quantification based on inductively coupled plasma in combination with mass spectrometry (ICP-MS) or optical emission spectroscopy (ICP-OES) enables investigators to measure multiple metals within a sample. For mass spectrometry based detection, the plasma is used to ionize the atoms, which are then separated on the basis of their mass to charge ratio (Husted et al., 2011). For detection by OES, atoms in the sample are excited by argon plasma and emit light at their characteristic wavelengths, which is used to identify the elements in the sample (Hou and Jones, 2000).

Theoretical detection limits of ICP-MS for most elements are at about 10 parts per trillion (ppt). When measuring complex biological samples, one has to consider matrix effects caused by the cell material, and measuring a standard curve in the cell paste is recommended to verify that matrix effects are negligible. The theoretical limit for ICP-OES is typically two- to three orders of magnitude higher than for ICP-MS with most elements detected at 1-10 parts per billion (ppb). Both detection methods have a linear dynamic detection range over several orders of magnitude (usually a linear dynamic range of $10^{6}$ to $10^{7}$ ) (Pröfrock and Prange, 2012).

Yet the use of ICP-MS for iron quantification has a limitation with respect to sensitivity when argon is used to generate the plasma. Polyatomic interferences, mainly due to argon oxide, have the same mass as the most abundant Fe isotope, ${ }^{56} \mathrm{Fe}$, and prohibit accurate measurement (Vogl et al., 2003). Therefore, in order to measure the iron content in a sample, a less abundant isotope of iron $\left({ }^{57} \mathrm{Fe}\right)$ can be measured. Another possibility is to use helium or hydrogen as a collision gas, which reduces the occurrence of interfering polyatomic complexes (Niemelä et al., 2003).
However, depending on the tuning of the collision gases, the background equivalent concentration (BEC) can be as high as $2 \mathrm{ppb}$. Therefore, to be able to measure accurate iron concentrations, the concentration of the sample has to be above the background level. Newer ICP-MS instruments utilize a combination of collision/reaction cell technologies with quadrupole or octupole mass analyzer to minimize interferences even further (Yip and Sham, 2007; Cvetkovic et al., 2010).

Because of the wide dynamic range, both the concentration of iron in the medium (1116 ppb) and in the cells can be quantified by either ICP-MS or ICP-OES. ICP-MS measurements (Agilent 7500) for different Chlamydomonas strains grown photoheterotrophically in iron-replete $(20 \mu \mathrm{M})$ media range between 5 and $40 \times 10^{7} \mathrm{Fe}$ atoms per cell (corresponding to 46 and 371 $\mathrm{ppb}$, when digested cell paste equivalent to $1 \times 10^{7}$ cells $/ \mathrm{mL}$ is measured) (Kropat et al., 2011). The cellular iron content of the strain CC- 125 is reduced from $12-25 \times 10^{7} \mathrm{Fe}$ atoms per cell to about $5 \times 10^{7} \mathrm{Fe}$ atoms per cell within $24 \mathrm{~h}$ of transfer from iron replete to iron-minus medium (Page et al., 2012). This iron content corresponds to about $110-230 \mathrm{ppb}$ for iron-replete and $46 \mathrm{ppb}$ Fe for iron starved cells (for sample preparation, see Figure 6).

As mentioned in section Cell Size, the cell size can vary between strains and growth conditions, and the calculation of metal content on a per cell basis, even though broadly used, is not ideal for comparisons between experiments conducted

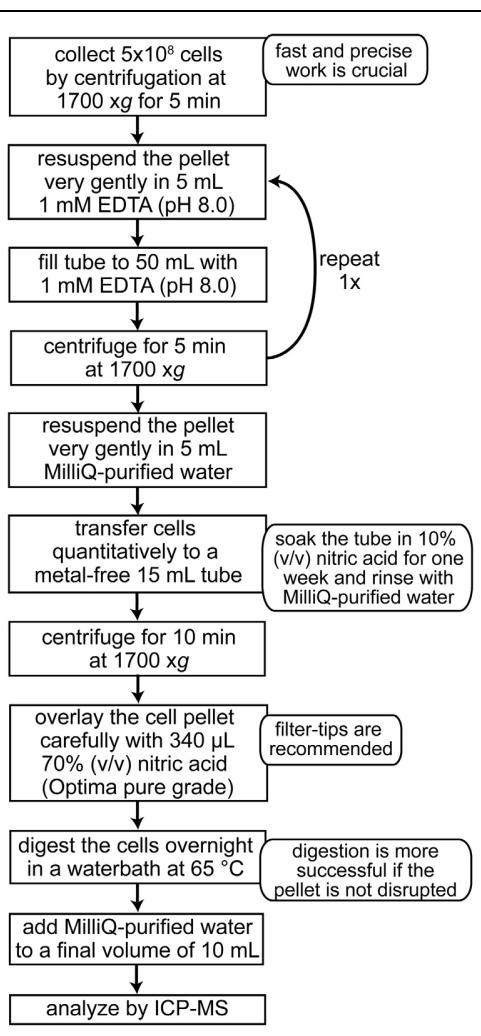

FIGURE 6 | Sample preparation of Chlamydomonas cells for metal analysis by ICP-MS. 
with different strains or under different growth conditions. Normalization based on the amount of other elements measured from the same sample would be desirable, but this normalization method should also be performed with caution, and efforts made to ensure that the chosen element's concentration does not change between test conditions. For instance, phosphorous content is commonly used to normalize the metal content between samples. However, Chlamydomonas manganese-deficient cells contain less phosphorous than replete cells (Allen et al., 2007b). The measurement of total organic carbon for normalization purposes may be a likely alternative.

\section{METHODS FOR MONITORING PHOTOSYNTHETIC PARAMETERS Chlorophyll assay}

Interveinal chlorosis is a classic symptom of poor iron nutrition in plants and is indeed a convenient indicator of iron status in agriculture (Mengel, 1994). It was originally attributed to the impact of low iron supply on the function of an iron-dependent step in Chl biosynthesis (Brown, 1956), but there may also be programmed degradation of Chl-containing proteins (Spiller et al., 1982; Moseley et al., 2002).

Unlike in land plants, the extent of chlorosis is dependent on the growth mode of Chlamydomonas culturesphotoheterotrophic vs. photoautotrophic. As a result, chlorosis by itself is not an absolute indicator of iron status. As mentioned above, the photosynthetic machinery is maintained longer in iron-limited cells grown in the light without acetate, while in the presence of acetate, degradation is apparent at early stages of suboptimal iron nutrition (Figures 1A,B) (Terauchi et al., 2010; Urzica et al., 2012).

For the measurement of Chl content, quantitative extraction of all Chl molecules from the cell is important. For Chlamydomonas this is routinely achieved with $80 \%(\mathrm{v} / \mathrm{v})$ acetone in methanol (Figure 7) (Porra et al., 1989; Moseley et al., 2000). Chl $a$ and $b$ concentrations are estimated according to the method of Porra et al. (1989). Even though the extinction coefficients in that method were determined for $80 \%$ acetone in aqueous solution, the estimation is accurate enough for comparing strains or conditions. In addition, extraction of Chl with $100 \%$ methanol has also been used in Chlamydomonas (Lynnes et al., 1998).

\section{Chlorophyll fluorescence}

Chlorophyll fluorescence is a fast, non-destructive way of characterizing the photosynthetic status of a cell. Absorbed photons generate excited Chls that can participate in photochemistry, dissipate the absorbed energy as heat (non-photochemical quenching) or return to the ground state accompanied by emission of light, referred to as $\mathrm{Chl}$ fluorescence. Since these individual fates of the excited state are mutually exclusive, the measurement of Chl fluorescence can be used to assess the efficiency of photochemical and non-photochemical quenching in the reaction center [the reader is encouraged to see (Maxwell and Johnson, 2000) and (Baker, 2008) for more details].

To probe the effect of iron nutrition on photosynthetic performance, Moseley et al. measured Chl fluorescence induction and decay kinetics of Chlamydomonas cells grown photoheterotrophically under different iron nutrition stages. The cells were darkadapted for at least $5 \mathrm{~min}$ and exposed to actinic light with a

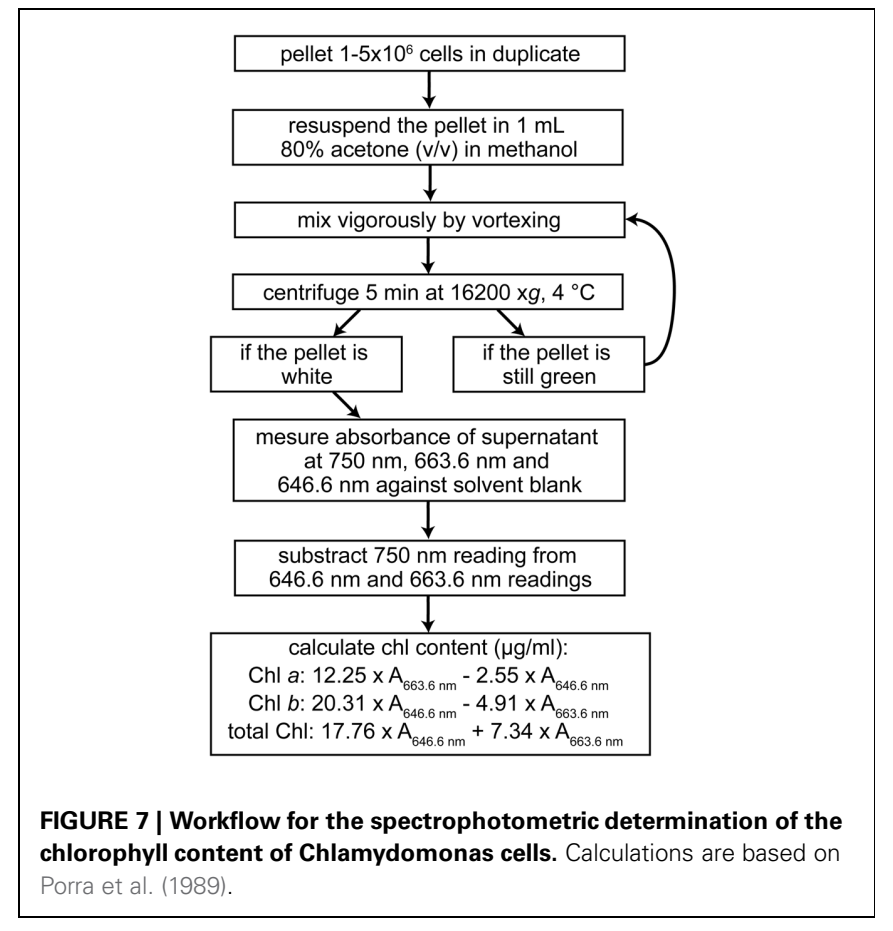

photon flux density of $\sim 60 \mu \mathrm{mol} / \mathrm{m}^{2} \mathrm{~s}$, using an open FluorCam detector to record the resulting fluorescence emission (Moseley et al., 2002). During dark-adaptation, the absence of photons and the consequent absence of electron output from PSII causes the $\mathrm{Q}_{\mathrm{A}}$ pool (the primary quinone electron acceptor of PSII) to become maximally oxidized. When these cells are exposed to actinic light, the Kautsky effect is observed: a fast increase in Chl fluorescence due to initial reduction of $\mathrm{Q}_{\mathrm{A}}$ followed by a slow decay due to its subsequent re-oxidization. Photoheterotrophic iron-deficient Chlamydomonas cells $(1 \mu \mathrm{M}$ Fe in the growth medium) display a slower fluorescence decay rate compared to iron replete cells, indicative of a reduced rate of $\mathrm{Q}_{\mathrm{A}}$ re-oxidation, possibly caused by impaired function of iron-containing complexes downstream of the PQ pool (Moseley et al., 2002). The slower decay rate is exacerbated in iron-limited cells $(0.25 \mu \mathrm{M} \mathrm{Fe}$ in the media) and accompanied by a slower rate of $\mathrm{Q}_{\mathrm{A}}$ reduction and a higher fluorescence yield suggesting impairment of PSII in addition to downstream electron transfer (Moseley et al., 2002).

The measurement of $\mathrm{Chl}$ fluorescence can also be used to determine photosynthetic parameters which help to determine the photosynthetic status of a cell. The ratio $F_{v} / F_{m}$ (maximum quantum efficiency of PSII) is a frequently used parameter, its value is relatively constant but decreases in stressed cells. Using a Hansatech FMS2 pulse-modulated fluorometer, Terauchi et al. measured the fluorescence of Chlamydomonas cells grown in the presence of different iron concentrations under both photoautotrophic and photoheterotrophic conditions. Cells were dark-adapted for $15 \mathrm{~min}$ and subsequently filtered onto $13-\mathrm{mm}$ diameter Milipore AP20 glass fiber filters prior to measurement (Terauchi et al., 2010). $F_{v}$ is defined as the difference between $F_{m}$ and $F_{0}$, with $F_{0}$ as the minimum fluorescence of the sample after dark-adaptation and $F_{m}$ the maximal Chl fluorescence after illumination with actinic light (Baker, 2008). Insufficient iron 
nutrition during photoheterotrophic growth of Chlamydomonas cells results in decreased $F_{v} / F_{m}$ from $0.7-0.74$ in iron-replete to 0.67 and 0.54 in 0.2 and $0.1 \mu \mathrm{M}$ Fe in the growth media, respectively. This decrease was not observed during iron-limitation in photoautotrophic growth conditions, indicating maintenance of photochemistry during this trophic growth regime (Figure 1B) (Terauchi et al., 2010).

\section{$77 \mathrm{~K}$ fluorescence}

Low-temperature $(77 \mathrm{~K})$ fluorescence emission spectra of whole Chlamydomonas cells or isolated thylakoid membranes are generally composed of major fluorescence bands around 685 and $715 \mathrm{~nm}$, which correspond to fluorescence emitted from Chl in light-harvesting antennae connected with PSII ( $685 \mathrm{~nm})$ and connected with PSI $(715 \mathrm{~nm})$ (Murata, 1968). This technique can be used to analyze changes in the interactions between lightharvesting antennae and the photosynthetic reaction centers. Functional disconnection of antennae from PSII or PSI appears as a shift in the fluorescence peaks, because LHC antennae not connected to photosystems show a different fluorescence maximum than those connected (Wollman and Bennoun, 1982). An increase in the amplitude of the PSI peak illustrates a state 1-to-state 2 transition, which is the reversible transfer of a fraction of LHCII antenna from PSII to PSI (Wollman and Delepelaire, 1984).

Low-temperature fluorescence spectra have revealed that poor iron nutrition affects the light harvesting antennae associated with both photosystems (Moseley et al., 2002; Naumann et al., 2005). During iron-deficient photoheterotrophic growth, the amplitude of the LHCI/PSI peak increases and shifts toward $705 \mathrm{~nm}$, which indicates a reduced energy transfer between the antennae and the reaction centers (higher amplitude) and a disconnection of LHCI antennae from PSI (shift). If the iron concentration in the media is further reduced $(0.1 \mu \mathrm{M})$, the LHCII antennae are also disconnected from PSII as indicated by a shift of the $685 \mathrm{~nm}$ peak toward $680 \mathrm{~nm}$ (Moseley et al., 2002). In contrast, in the absence of acetate, the amplitude of the LCHI/PSI peak decreases, and there is only a small shift after extended iron-deplete growth (Busch et al., 2008).

Low temperature $77 \mathrm{~K}$ fluorescence has also been applied to characterize mutants involved in the iron deficiency response. In the pgrl1-28 knock-down mutant for example, the antennae disconnection is more sensitive to iron-deficiency. An increase in amplitude and a small blue shift (from 713 to $709 \mathrm{~nm}$ ) was observed for the mutant but not the wild-type at $3 \mu \mathrm{M} \mathrm{Fe}$ in the media (Petroutsos et al., 2009).

\section{REFERENCES}

Allen, M. D., del Campo, J. A., Kropat, J., and Merchant, S. S. (2007a). FEA1, FEA2, and $F R E 1$, encoding two homologous secreted proteins and a candidate ferrireductase, are expressed coordinately with FOX1 and FTR1 in iron-deficient Chlamydomonas reinhardtii. Eukaryot. Cell 6, 1841-1852. doi: 10.1128/EC.00205-07

Allen, M. D., Kropat, J., Tottey, S., del Campo, J. A., and Merchant,

\section{FUTURE DIRECTION}

The role of iron in the metabolism of Chlamydomonas has been studied extensively; however, several questions remain to be investigated. Most iron nutrition studies have focused on growth in the presence of light and acetate. An outstanding question relates to the relationship between iron nutrition and carbon metabolism. Several studies have noted that the response of Chlamydomonas to iron status can vary drastically depending on whether acetate is present or not. Both the physiology as evaluated with growth kinetics, iron uptake and photosynthetic efficiency, and the transcriptome have revealed markedly different phenomena. How carbon source impacts the decision to maintain photosynthesis is not known. The relationship between Chlamydomonas iron metabolism and heterotrophic growth (in the dark with acetate) or anaerobiosis have been largely left uninvestigated.

How iron status is linked to changes in transcription is also unknown for Chlamydomonas. A number of transcription factors and regulatory proteins are known components of iron homeostasis in land plants (Vigani et al., 2013), but the extent to which there is overlap in the iron-regulatory networks between green algae and land plants is unknown. The recent iron-nutrition transcriptome of Chlamydomonas has provided some targets, which include eleven putative transcription regulators whose mRNA abundance is increased in iron-limited cells (Urzica et al., 2012). Of these putative regulators is a potential functional ortholog of the A. thaliana E3 ubiquitin ligase BTS and a bHLH transcription factor orthologous to bHLH115. However, as of yet, the functions of these putative regulators have not been confirmed in Chlamydomonas. Multiple types of ironresponsive elements (FeREs) have been uncovered (Deng and Eriksson, 2007; Fei et al., 2009, 2010), suggesting the involvement of more than one transcription factor. Also, the different responses to iron nutrition depending on carbon source suggest that the iron-regulatory network in Chlamydomonas may be complex.

\section{ACKNOWLEDGMENTS}

This work was supported by the Division of Chemical Sciences, Geosciences, and Biosciences, Office of Basic Energy Sciences of the U.S Department of Energy (DE-FD02-04ER15529). Crysten E. Blaby-Haas acknowledges support from an Individual Kirschstein National Research Service Award (GM100753). We would like to thank Janette Kropat, Rikard Fristedt, Sean Gallaher, and Ian Blaby for critical review of the manuscript.

Becker, B. (2013). Snow ball earth and the split of Streptophyta and Chlorophyta. Trends Plant Sci. 18, 180-183.

Ben-Shem, A., Frolow, F., and Nelson, N. (2003). Crystal structure of plant photosystem I. Nature 426, 630-635. doi: 10.1038/ nature 02200

Blaby-Haas, C. E., and Merchant, S. S. (2013). "Sparing and salvaging metals in chloroplasts," in Encyclopedia of Inorganic and
Bioinorganic Chemistry. Metals in Cells, eds V. Culotta, and R. A. Scott (Chichester: John Wiley and Sons Ltd.) (in press).

Brown, J. (1956). Iron chlorosis. Ann. Rev. Plant Physiol. 7, 171-190.

Buckhout, T. J., Yang, T. J. W., and Schmidt, W. (2009). Early irondeficiency-induced transcriptional changes in Arabidopsis roots as revealed by microarray analyses. BMC Genomics 10:147. doi: 10.1186/1471-2164-10-147 
Busch, A., Rimbauld, B., Naumann, B., Rensch, S., and Hippler, M. (2008). Ferritin is required for rapid remodeling of the photosynthetic apparatus and minimizes photooxidative stress in response to iron availability in Chlamydomonas reinhardtii. Plant J. 55, 201-211. doi: 10.1111/j.1365313X.2008.03490.x

Chen, Y., and Barak, P. (1982). Iron nutrition of plants in calcareous soils. Adv. Agron. 35, 217-240.

Cox, C. D. (1994). Deferration of laboratory media and assays for ferric and ferrous ions. Methods Enzymol. 235, 315-329. doi: 10.1016/0076687935150-3

Cvetkovic, A., Menon, A. L., Thorgersen, M. P., Scott, J. W., Poole, F. L. 2nd., Jenney, F. E. Jr., et al. (2010). Microbial metalloproteomes are largely uncharacterized. Nature 466, 779-782. doi: 10.1038/nature09265

Deng, X., and Eriksson, M. (2007). Two iron-responsive promoter elements control expression of FOX1 in Chlamydomonas reinhardtii. Eukaryot. Cell 6, 2163-2167. doi: 10.1128/EC.00324-07

Dix, D. R., Bridgham, J. T., Broderius, M. A., Byersdorfer, C. A., and Eide, D. J. (1994). The FET4 gene encodes the low affinity $\mathrm{Fe}(\mathrm{II})$ transport protein of Saccharomyces cerevisiae. J. Biol. Chem. 269, 26092-26099.

Docampo, R., de Souza, W., Miranda, K., Rohloff, P., and Moreno, S. N. (2005). Acidocalcisomes - conserved from bacteria to man. Nat. Rev. Microbiol. 3, 251-261. doi: 10.1038/nrmicro1097

Eide, D., Broderius, M., Fett, J., and Guerinot, M. L. (1996). A novel iron-regulated metal transporter from plants identified by functional expression in yeast. Proc. Natl. Acad. Sci. U.S.A. 93, 5624-5628.

Emerson, L. R., Nau, M. E., Martin, R. K., Kyle, D. E., Vahey, M., and Wirth, D. F. (2002). Relationship between chloroquine toxicity and iron acquisition in Saccharomyces cerevisiae. Antimicrob. Agents Chemother. 46, 787-796. doi: 10.1128/AAC.46.3.787-796.2002

Fei, X., Eriksson, M., Li, Y., and Deng, X. (2010). A novel negative fe-deficiency-responsive element and a TGGCA-type-like FeRE control the expression of FTR1 in Chlamydomonas reinhardtii. J. Biomed. Biotechnol. 2010:790247. doi: 10.1155/2010/790247

Fei, X., Eriksson, M., Yang, J., and Deng, X. (2009). An Fe deficiency responsive element with a core sequence of TGGCA regulates the expression of FEA1 in Chlamydomonas reinharditii. J. Biochem. 146, 157-166. doi: 10.1093/jb/mvp056

Fischer, B. B., Wiesendanger, M., and Eggen, R. I. L. (2006). Growth condition-dependent sensitivity, photodamage and stress response of Chlamydomonas reinhardtii exposed to high light conditions. Plant Cell Physiol. 47, 1135-1145. doi: $10.1093 / \mathrm{pcp} / \mathrm{pcj} 085$

Giehl, R. F. H., Lima, J. E., and von Wirén, N. (2012). Localized iron supply triggers lateral root elongation in Arabidopsis by altering the AUX1-mediated Auxin distribution. Plant cell 24, 33-49. doi: 10.1105/tpc.111.092973

Grossman, A. R., Croft, M., Gladyshev, V. N., Merchant, S. S., Posewitz, M C., Prochnik, S., et al. (2007). Novel metabolism in Chlamydomonas through the lens of genomics. Curr. Opin. Plant Biol. 10, 190-198. doi: 10.1016/j.pbi.2007.01.012

Herbik, A., Bölling, C., and Buckhout, T. J. (2002). The involvement of a multicopper oxidase in iron uptake by the green algae Chlamydomonas reinhardtii. Plant Physiol. 130 2039-2048. doi: 10.1104/pp.013060

Hong, S., Kim, S. A., Guerinot, M. L., and McClung, C. R. (2013). Reciprocal interaction of the circadian clock with the iron homeostasis network in Arabidopsis. Plant Physiol. 161, 893-903. doi: 10.1104/pp.112.208603

Hou, X., and Jones, B. T. (2000). "Inductively coupled plasmaoptical emission spectrometry," in Encyclopedia of Analytical Chemistry, ed R. A. Meyers (Chichester: John Wiley and Sons Ltd.), 9468-9485.

Husted, S., Persson, D. P., Laursen, K. H., Hansen, T. H., Pedas, P. Schiller, M., et al. (2011). The role of atomic spectrometry in plant science. J. Anal. At. Spectrom. 26, 52-79. doi: 10.1039/c0ja00058b

Hutner, S. H., Provasoli, L., Schatz, A., and Haskins, C. P. (1950). Some approaches to the study of the role of metals in the metabolism of microorganisms. Proc. Am. Phil. Soc. 94, 152-170

Jacobs, J., Pudollek, S., Hemschemeier, A., and Happe, T. (2009). A novel anaerobically induced ferredoxin in Chlamydomonas reinhardtii. FEBS Lett. 583, 325-329. doi: 10.1016/j.febslet.2008.12.018

Jo, W. J., Kim, J. H., Oh, E., Jaramillo, D., Holman, P., Loguinov, A. V., et al. (2009). Novel insights into iron metabolism by integrating deletome and transcriptome analysis in an iron deficiency model of the yeast Saccharomyces cerevisiae. BMC Genomics 10:130. doi 10.1186/1471-2164-10-130

Kroll, H., Knell, M., Powers, J., and Simonian, J. (1957). A phenolic analog of ethylenediaminetetraacetic acid. J. Am. Chem. Soc. 79, 2024-2025. doi: 10.1021/ja01565a075

Kropat, J., Hong-Hermesdorf, A., Casero, D., Ent, P., Castruita, M. Pellegrini, M., et al. (2011). A revised mineral nutrient supplement increases biomass and growth rate in Chlamydomonas reinhardtii. Plant J. 66, 770-780. doi: 10.1111/j.1365-313X.2011.04537.x

La Fontaine, S., Quinn, J. M. Nakamoto, S. S., Page, M. D. Göhre, V., Moseley, J. L., et al. (2002). Copper-dependent iron assimilation pathway in the model photosynthetic eukaryote Chlamydomonas reinhardtii. Eukaryot. Cell 1, 736-757. doi: 10.1128/EC.1.5.736-757.2002

Lanquar, V., Lelièvre, F., Bolte, S. Hamès, C., Alcon, C., Neumann, D., et al. (2005). Mobilization of vacuolar iron by AtNRAMP3 and AtNRAMP4 is essential for seed germination on low iron EMBO J. 24, 4041-4051. doi: 10.1038/sj.emboj.7600864

Lesuisse, E., Simon-Casteras, M., and Labbe, P. (1998). Siderophoremediated iron uptake in Saccharomyces cerevisiae: the SIT1 gene encodes a ferrioxamine $B$ permease that belongs to the major facilitator superfamily. Microbiology 144, 3455-3462. doi: 10.1099/00221287-144-12-3455

Long, J. C., and Merchant, S. S. (2008). Photo-oxidative stress impacts the expression of genes encoding iron metabolism components in Chlamydomonas. Photochem. Photobiol. 84, 1395-1403. doi: 10.1111/j.1751-1097.2008.00451.x

Long, J. C., Sommer, F., Allen, M. D., Lu, S. F., and Merchant, S. S. (2008) FER1 and FER2 encoding two ferritin complexes in Chlamydomonas reinhardtii chloroplasts are regulated by iron. Genetics 179 , 137-147. doi: 10.1534/genetics.107. 083824

Lynnes, J. A., Derzaph, T. L. M., and Weger, H. G. (1998). Iron limitation results in induction of ferricyanide reductase and ferric chelate reductase activities in Chlamydomonas reinhardtii. Planta 204, 360-365. doi: $10.1007 /$ s004250050267
Malasarn, D., Kropat, J., Hsieh, S I., Finazzi, G., Casero, D., Loo, J. A., et al. (2013). Zinc deficiency impacts $\mathrm{CO}_{2}$ assimilation and disrupts copper homeostasis in Chlamydomonas reinhardtii. J. Biol. Chem. 288, 10672-10683. doi: 10.1074/jbc.M113.455105

Matsumura, K., Yagi, T., and Yasuda, K. (2003). Role of timer and sizer in regulation of Chlamydomonas cell cycle. Biochem. Biophys. Res. Commun. 306, 1042-1049. doi: 10.1016/S0006-291X(03)01089-1

Maxwell, K., and Johnson, G. N. (2000). Chlorophyll fluorescence - a practical guide. J. Exp. Bot. 51, 659-668. doi: 10.1093/jexbot/51.345.659

Mengel, K. (1994). Iron availability in plant tissues - iron chlorosis on calcareous soils. Plant Soil 165, 275-283. doi: 10.1007/BF00008070

Merchant, S. S., Allen, M. D., Kropat, J., Moseley, J. L., Long, J. C., Tottey, S., et al. (2006). Between a rock and a hard place: trace element nutrition in Chlamydomonas. Biochim. Biophys. Acta 1763, 578-594. doi: 10.1016/j.bbamcr.2006.04.007

Mercier, A., Pelletier, B., and Labbé, S. (2006). A Transcription factor cascade involving Fep1 and the CCAAT-binding factor Php4 regulates gene expression in response to iron deficiency in the fission yeast Schizosaccharomyces pombe. Eukaryot. Cell 5, 1866-1881. doi: 10.1128/EC.00199-06

Moore, J. K., Doney, S. C., Glover, D. M., and Fung, I. Y. (2002) Iron cycling and nutrient-limitation patterns in surface waters of the World Ocean. Deep Sea Res. II 49, 463-507. doi: 10.1016/S0967-06 4500109-6

Moseley, J. L., Allinger, T., Herzog, S., Hoerth, P., Wehinger, E., Merchant, S., et al. (2002). Adaptation to Fe-deficiency requires remodeling of the photosynthetic apparatus. EMBO J. 21, 6709-6720. doi: 10.1093/emboj/cdf666

Moseley, J. L., Quinn, J., Eriksson, M., and Merchant, S. (2000). The $\mathrm{Crdl}$ gene encodes a putative di-iron enzyme required for photosystem I accumulation in copper deficiency and hypoxia in Chlamydomonas reinhardtii. EMBO J. 19, 2139-2151. doi: 10.1093/emboj/19.10.2139

Murakami, A., Fujita, Y., Nemson, J. A., and Melis, A. (1997). Chromatic regulation in Chlamydomonas reinhardtii: time course of photosystem stoichiometry adjustment following a shift in growth light quality. Plant Cell Physiol. 38, 188-193. 
Murata, N. (1968). Fluorescence of chlorophyll in photosynthetic systems. IV. Induction of various emissions at low temperatures. Bioenergetics 162, 106-121. doi: 10.1016/0005-272890219-3

Nagasaka, S., and Yoshimura, E. (2008). External iron regulates polyphosphate content in the acidophilic, thermophilic alga Cyanidium caldarium. Biol. Trace Elem. Res. 125, 286-289. doi: 10.1007/s12011-0088177-9

Naumann, B., Busch, A., Allmer, J., Ostendorf, E., Zeller, M., Kirchhoff, H., et al. (2007). Comparative quantitative proteomics to investigate the remodeling of bioenergetic pathways under iron deficiency in Chlamydomonas reinhardtii. Proteomics 7, 3964-3979. doi: 10.1002/pmic. 200700407

Naumann, B., Stauber, E. J., Busch, A., Sommer, F., and Hippler, M. (2005). N-terminal processing of Lhca3 is a key step in remodeling of the photosystem I-light-harvesting complex under iron deficiency in Chlamydomonas reinhardtii. J. Biol. Chem. 280, 20431-20441. doi: 10.1074/jbc.M414486200

Niemelä, M., Perämäki, P., Kola, H., and Piispanen, J. (2003). Determination of arsenic, iron and selenium in moss samples using hexapole collision cell, inductively coupled plasma-mass spectrometry. Anal. Chim. Acta 493, 3-12. doi: 10.1016/S0003-267000819-5

Page, M. D., Allen, M. D., Kropat, J., Urzica, E. I., Karpowicz, S. J., Hsieh, S. I., et al. (2012). Fe sparing and $\mathrm{Fe}$ recycling contribute to increased superoxide dismutase capacity in iron-starved Chlamydomonas reinhardtii. Plant Cell 24, 2649-2665. doi: 10.1105/tpc. 112.098962

Page, M. D., Kropat, J., Hamel, P. P., and Merchant, S. S. (2009). Two Chlamydomonas CTR copper transporters with a novel cys-met motif are localized to the plasma membrane and function in copper assimilation. Plant Cell 21, 928-943. doi: $10.1105 /$ tpc. 108.064907

Paz, Y., Shimoni, E., Weiss, M., and Pick, U. (2007). Effects of iron deficiency on iron binding and internalization into acidic vacuoles in Dunaliella salina. Plant Physiol. 144, 1407-1415. doi: 10.1104/pp.107.100644

Pelletier, B., Trott, A., Morano, K. A., and Labbé, S. (2005). Functional characterization of the ironregulatory transcription factor Fep1 from Schizosaccharomyces pombe.
J. Biol. Chem. 280, 25146-25161. doi: 10.1074/jbc.M502947200

Petroutsos, D., Terauchi, A. M., Busch, A., Hirschmann, I., Merchant, S. S., Finazzi, G., et al. (2009) PGRL1 participates in iron-induced remodeling of the photosynthetic apparatus and in energy metabolism in Chlamydomonas reinhardtii. J. Biol. Chem. 284, 32770-32781. doi: 10.1074/jbc. M109.050468

Porra, R. J., Thompson, W. A., and Kriedemann, P. E. (1989). Determination of accurate extinction coefficients and simultaneous equations for assaying chlorophylls $a$ and $b$ extracted with four different solvents: verification of the concentration of chlorophyll standards by atomic absorption spectroscopy. Bioenergetics 975, 384-394. doi: 10.1016/S0005-2728 80347-0

Pröfrock, D., and Prange, A. (2012). Inductively Coupled Plasma-Mass Spectrometry (ICP-MS) for quantitative analysis in environmental and life sciences: a review of challenges, solutions, and trends. Appl. Spectrosc. 66, 843-868. doi: 10.1366/12-06681

Quinn, J. M., and Merchant, S. S. (1998). Copper-responsive gene expression during adaptation to copper deficiency. Methods Enzymol. 297, 263-279. doi: 10.1016/S0076-687997020-68799 7023

Rochaix, J.-D. (2002). Chlamydomonas, a model system for studying the assembly and dynamics of photosynthetic complexes. FEBS Lett. 529, 34-38. doi: 10.1016/S0014579303181-2

Rubinelli, P., Siripornadulsil, S., GaoRubinelli, F., and Sayre, R. T. (2002). Cadmium- and iron-stressinducible gene expression in the green alga Chlamydomonas reinhardtii: evidence for $\mathrm{H} 43$ protein function in iron assimilation. Planta 215, 1-13. doi: 10.1007/s00425-0010711-3

Ruiz, F. A., Marchesini, N., Seufferheld, M., Govindjee, and Docampo, R. (2001). The polyphosphate bodies of Chlamydomonas reinhardtii possess a proton-pumping pyrophosphatase and are similar to acidocalcisomes. J. Biol. Chem. 276, 46196-46203. doi: 10.1074/jbc.M105268200

Salomé, P. A., Oliva, M., Weigel, D., and Krämer, U. (2013). Circadian clock adjustment to plant iron status depends on chloroplast and phytochrome function. $Е M B O$ J. 32, 511-523. doi: 10.1038/emboj. 2012.330

Semin, B. K., Davletshina, L. N., Novakova, A. A., Kiseleva, T. Y. Lanchinskaya, V. Y., Aleksandrov, A. Y., et al. (2003). Accumulation of ferrous iron in Chlamydomonas reinhardtii. Influence of $\mathrm{CO}_{2}$ and anaerobic induction of the reversible hydrogenase. Plant Physiol. 131, 1756-1764. doi: 10.1104/pp.102.018200

Spiller, S. C., Castelfranco, A. M., and Castelfranco, P. A. (1982). Effects of iron and oxygen on chlorophyll biosynthesis I. In vivo observations on iron and oxygen-deficient plants. Plant Physiol. 69, 107-111. doi: 10.1104/pp.69.1.107

Stookey, L. L. (1970). Ferrozine new spectrophotometric reagent for iron. Anal. Chem. 42, 779-781. doi: 10.1021/ac60289a016

Terauchi, A. M., Peers, G., Kobayashi, M. C., Niyogi, K. K., and Merchant, S. S. (2010). Trophic status of Chlamydomonas reinhardtii influences the impact of iron deficiency on photosynthesis. Photosynth. Res. 105, 39-49. doi: 10.1007/s11120010-9562-8

Terzulli, A., and Kosman, D. J. (2010). Analysis of the highaffinity iron uptake system at the Chlamydomonas reinhardtii plasma membrane. Eukaryot Cell 9, 815-826. doi: 10.1128/EC. 00310-09

Thimm, O., Essigmann, B., Kloska, S. Altmann, T., and Buckhout, T. J. (2001). Response of Arabidopsis to iron deficiency stress as revealed by microarray analysis. Plant Physiol. 127, 1030-1043. doi: 10.1104/pp.010191

Tottey, S., Block, M. A., Allen, M., Westergren, T., Albrieux, C., Scheller, H. V., et al. (2003) Arabidopsis CHL27, located in both envelope and thylakoid membranes, is required for the synthesis of protochlorophyllide. Proc. Natl. Acad. Sci. U.S.A. 100 16119-16124. doi: 10.1073/pnas.21 36793100

Umen, J. D. (2005). The elusive sizer Curr. Opin. Cell Biol. 17, 435-441. doi: 10.1016/j.ceb.2005.06.001

Urzica, E. I., Casero, D., Yamasaki, H., Hsieh, S. I., Adler, L. N., Karpowicz, S. J., et al. (2012). Systems and trans-system level analysis identifies conserved iron deficiency responses in the plant lineage. Plant Cell 24 3921-3948. doi: 10.1105/tpc.112. 102491

Vance, P., and Spalding, M. H. (2005). Growth, photosynthesis, and gene expression in Chlamydomonas over a range of $\mathrm{CO}_{2}$ concentrations and $\mathrm{CO}_{2} / \mathrm{O}_{2}$ ratios: $\mathrm{CO}_{2}$ regulates multiple acclimation states. Can. J. Bot. 83, 796-809. doi: 10.1139/b05-064

Vert, G., Grotz, N., Dédaldéchamp, F., Gaymard, F., Guerinot, M. L., Briat, J.-F., et al. (2002). IRT1, an arabidopsis transporter essential for iron uptake from the soil and for plant growth. Plant Cell 14, 1223-1233. doi: $10.1105 /$ tpc. 001388

Vigani, G., Zocchi, G., Bashir, K., Philippar, K., and Briat, J.-F. (2013). Signals from chloroplasts and mitochondria for iron homeostasis regulation. Trends Plant Sci. 8, 305-311. doi: 10.1016/j.tplants. 2013.01.006

Vogl, J., Klingbeil, P., Pritzkow, W., and Riebe, G. (2003). High accuracy measurements of $\mathrm{Fe}$ isotopes using hexapole collision cell MC-ICP-MS and isotope dilution for certification of reference materials. J. Anal. Atom. Spectrom. 18, 1125-1132. doi: 10.1039/B301812A

Wang, H.-Y., Klatte, M., Jakoby, M., Bäumlein, H., Weisshaar B., and Bauer, P. (2007). Iron deficiency-mediated stress regulation of four subgroup Ib BHLH genes in Arabidopsis thaliana. Planta 226, 897-908. doi: 10.1007/s00425-007-0535-x

Weger, H. G. (1999). Ferric and cupric reductase activities in the green alga Chlamydomonas reinhardtii: Experiments using iron-limited chemostats. Planta 207, 377-384 doi: 10.1007/s004250050495

Weger, H. G., and Espie, G. S. (2000). Ferric reduction by iron-limited Chlamydomonas cells interacts with both photosynthesis and respiration. Planta 210, 775-781. doi: $10.1007 / \mathrm{s} 004250050679$

Wollman, F.-A., and Bennoun, P. (1982). A new chlorophyll-protein complex related to photosystem I in Chlamydomonas reinhardii. Bioenergetics 680, 352-360. doi: 10.1016/0005-272890149-9

Wollman, F.-A., and Delepelaire, P. (1984). Correlation between changes in light energy distribution and changes in thylakoid membrane polypeptide phosphorylation in Chlamydomonas reinhardtii. J. Cell Biol. 98, 1-7. doi: 10.1083/jcb.98.1.1 $\mathrm{Xu}, \mathrm{W} .$, Barrientos, T., and Andrews, N. C. (2013). Iron and copper in mitochondrial diseases. Cell Metab. 17, 319-328. doi: 10.1016/j.cmet.2013.02.004

Xue, X., Collins, C. M., and Weger, H. G. (1998). The energetics of 
extracellular $\mathrm{Fe}(\mathrm{III})$ reduction by iron-limited Chlamydomonas reinhardtii (Chlorophyta). J. Phycol. 34, 939-944. doi: 10.1046/j.15298817.1998.340939.x

Yang, T. J. W., Lin, W.-D., and Schmidt, W. (2010). Transcriptional profiling of the Arabidopsis iron deficiency response reveals conserved transition metal homeostasis networks. Plant Physiol. 152, 2130-2141. doi: 10.1104/pp.109.152728

Yip, Y.-c., and Sham, W.c. (2007). Application of collision/reaction-cell technology in isotope dilution mass spectrometry.
Trends Anal. Chem. 26, 727-743. doi: 10.1016/j.trac.2007.03.007

Zhang, L., Happe, T., and Melis, A. (2002). Biochemical and morphological characterization of sulfur-deprived and H2-producing Chlamydomonas reinhardtii (green alga). Planta 214, 552-561. doi: $10.1007 / \mathrm{s} 004250100660$

Zheng, L., Huang, F., Narsai, R., Wu, J., Giraud, E., He, F., et al. (2009). Physiological and transcriptome analysis of iron and phosphorus interaction in rice seedlings. Plant Physiol. 151, 262-274. doi: 10.1104/pp.109.141051
Conflict of Interest Statement: The authors declare that the research was conducted in the absence of any commercial or financial relationships that could be construed as a potential conflict of interest.

Received: 24 May 2013; paper pending published: 17 June 2013; accepted: 09 August 2013; published online: 02 September 2013.

Citation: Glaesener AG, Merchant SS and Blaby-Haas CE (2013) Iron economy in Chlamydomonas reinhardtii. Front. Plant Sci. 4:337. doi: 10.3389/fpls. 2013.00337
This article was submitted to Plant Nutrition, a section of the journal Frontiers in Plant Science.

Copyright (c) 2013 Glaesener, Merchant and Blaby-Haas. This is an open-access article distributed under the terms of the Creative Commons Attribution License (CC BY). The use, distribution or reproduction in other forums is permitted, provided the original author(s) or licensor are credited and that the original publication in this journal is cited, in accordance with accepted academic practice. No use, distribution or reproduction is permitted which does not comply with these terms. 